\title{
Autism Symptoms and Internalizing Psychopathology in Girls and Boys with Autism Spectrum Disorders
}

\author{
Marjorie Solomon • Meghan Miller • \\ Sandra L. Taylor · Stephen P. Hinshaw • \\ Cameron S. Carter
}

Published online: 26 March 2011

(C) The Author(s) 2011. This article is published with open access at Springerlink.com

\begin{abstract}
Findings regarding phenotypic differences between boys and girls with ASD are mixed. We compared autism and internalizing symptoms in a sample of 8-18 year-old girls $(n=20)$ and boys $(n=20)$ with ASD and typically developing (TYP) girls $(n=19)$ and boys $(n=17)$. Girls with ASD were more impaired than TYP girls but did not differ from boys with ASD in autism symptoms. In adolescence, girls with ASD had higher internalizing symptoms than boys with ASD and TYP girls, and higher symptoms of depression than TYP girls. Girls ages 8-18 with ASD resemble boys with ASD and not TYP girls, and appear to be at increased risk for affective symptoms in the teen years.
\end{abstract}

Keywords Sex differences · Autism · Girls · Internalizing psychopathology $\cdot$ Gender paradox

M. Solomon · C. S. Carter

Department of Psychiatry \& Behavioral Sciences,

University of California, Davis, Davis, CA, USA

M. Solomon · M. Miller

MIND Institute, University of California, Davis,

Davis, CA, USA

M. Miller · S. P. Hinshaw

Department of Psychology, University of California, Berkeley,

Berkeley, CA, USA

S. L. Taylor

Clinical and Translational Science Center, Davis

School of Medicine, University of California, Davis, CA, USA

M. Solomon $(\square)$

2825 50th Street, Sacramento, CA 95817, USA

e-mail: marjorie.solomon@ucdmc.ucdavis.edu

\section{Introduction}

Autism spectrum disorders (ASD), including autism, highfunctioning autism (HFA), Asperger's Syndrome (AS), and Pervasive Developmental Disorder-Not Otherwise Specified (PDD-NOS), occur with a prevalence of 1 in 110 (Centers for Disease Control 2009). Male predominance is estimated at 4-1 (Fombonne 2003). Consequently, there has been relatively little research on girls with ASD. Extant findings are complex and difficult to interpret.

There are two schools of thought regarding sex differences in ASD. Some have theorized that being female confers protection against autism traits because of sex differences in neuroendocrine function. One such argument suggests that higher levels of oxytocin, which encourage nurturance and affiliation, provide protection in girls against the development of autistic traits (Carter 2007). Alternatively, it has been proposed that high levels of fetal testosterone may predispose boys to have "extreme male brains," characterized by phenotypes involving elevated "systematizing" (focus on inanimate systems and details) versus "empathizing" (focus on interpersonal orientation) (BaronCohen et al. 2005). Both lead to the same conclusion that, despite skill deficits relative to typically developing (TYP) females, girls with ASD symptoms may not be diagnosed because of milder symptom presentation (Constantino and Todd 2003) and referral biases (Posserud et al. 2006), and given that they are still more socially adept than boys with and without ASD based on their relative strengths in social skills and caretaking (Holliday-Willey 1999; Maccoby 1998). It is thus important to directly compare girls with ASD to TYP girls to more fully understand implications of being a girl with ASD (Koenig and Tsatsanis 2005).

The second school of thought is that girls with ASD are more severely impaired than boys with ASD. According to 
the 'gender paradox' hypothesis (Eme 1992), the least frequently affected sex is more severely impaired. This gender paradox has been explained using two types of models: (1) polygenetic multiple-threshold models, which suggest that females require a higher genetic/environmental load to be affected; and (2) constitutional variability models, which propose that greater genetic variability in males produces higher rates of less severe manifestations of disorders, while females are more likely to be affected in cases where there is a pathological event (e.g., brain damage) (Eme 1992). Both of these models suggest that there will be more impairment in affected females.

Indeed, some work suggests that girls with ASD are more severely impaired than boys with the disorders. In samples including children with higher cognitive abilities, a recent study found that, relative to age, ASD symptom, and cognitively-matched males, female toddlers exhibited greater deficits in aspects of communication and social competence (Carter et al. 2007). Consistent with this pattern, investigators have reported that, across a wide age range, girls with ASD have fewer friendships in a higherfunctioning sample (McLennan et al. 1993), and more communication deficits and greater adaptive behavior impairments in a lower functioning sample (Banach et al. 2009) than boys with ASD. Although children with autism are more commonly male, studies have shown that the sex ratio approaches equality in lower-functioning samples and that boys are over-represented in higher-functioning populations (Fombonne 2003; Lord et al. 1982; Tsai et al. 1981; Volkmar et al. 1993; Wing 1981; Yeargin-Allsopp et al. 2003), consistent with the gender paradox hypothesis.

However, not all studies have documented sex differences. Some have found comparable levels of impairment in girls and boys with autism across high functioning samples (Holtmann et al. 2007), low functioning samples (Pilowsky et al. 1998; Tsai and Beisler 1983), and samples including a range of functioning levels (Lord et al. 2000). Other studies have shown that boys with ASD exhibit higher levels of repetitive behaviors in both lower-functioning (Hartley and Sikora 2009) and higher-functioning samples (McLennan et al. 1993), and higher levels of stereotypic play in a lower-functioning sample (Lord et al. 1982). Inconsistent matching strategies, diagnostic criteria, and participant ages make interpretation of these findings difficult. Furthermore, in clinic-referred samples versus community/non-referred samples, girls may have to reach a higher overall level of symptoms in order to present for treatment (see Gaub and Carlson 1997 for a parallel finding in ADHD).

In addition to understanding sex differences in ASD symptoms, an important and clinically significant issue in the ASD population is whether girls with ASD are at elevated risk for affective disorders. Boys and girls show similar levels of depression in childhood, but levels in girls become dramatically greater in adolescence (NolenHoeksema and Girgus 1994). Additionally, individuals with ASD demonstrate increased internalizing psychopathology relative to TYP individuals (Kim et al. 2000; Lainhart and Folstein 1994; Mazefsky et al. 2010; Sukhodolsky et al. 2008). Therefore, girls with ASD may be at especially high risk for internalizing psychopathology because of the "double hit" conferred by sex and diagnostic influences.

In sum, sex differences in the ASD phenotype remain poorly understood. To our knowledge, no studies have focused on sex differences in high-functioning preadolescents and adolescents, directly compared TYP girls and girls with ASD, or examined sex differences in the presentation of affective disorders in ASD. The goal of the current study was to address these important gaps in the literature. The first aim was to investigate whether our clinically-referred high-functioning sample of boys and girls differed in ASD symptoms using independent assessments of language, social, and repetitive behavior symptoms that were not used to make the ASD diagnosis. Although there are mixed findings in the literature, evidence for the gender paradox hypothesis has been found in very low functioning ASD samples, and our sample was higher functioning. Thus, consistent with theories that neuroendocrine factors are protective against ASD traits, we hypothesized that girls with ASD would show fewer symptoms of social behavior impairments than boys with ASD, and comparable symptom levels to TYP girls on parent-reported measures not used to make the ASD diagnosis. Based on the literature, we also predicted that boys with ASD would show higher levels of restricted and repetitive behaviors than all other groups. Last, we aimed to investigate whether girls with ASD were at greater risk for internalizing problems than TYP girls and boys with ASD, as would be predicted by a "double hit" perspective. Hypotheses were tested using clinician-, parent-, and childreport measures.

\section{Method}

\section{Participants}

A total of 76 children (ages 8-11) and adolescents (ages 12-18) participated in this study. Four age-matched groups were formed: 20 girls with ASD (including HFA, AS, and PDD-NOS), 20 boys with ASD, 19 TYP girls, and 17 TYP boys. The ASD groups were matched on IQ. These groups were further divided such that approximately half of each were children and half were adolescents (adolescent $n \mathrm{~s}=10$ for girls with ASD, 10 for boys with ASD, 9 for 
Table 1 Participant characteristics

\begin{tabular}{|c|c|c|c|c|c|c|c|c|c|c|}
\hline \multirow[t]{2}{*}{ Variable } & \multicolumn{2}{|c|}{$\begin{array}{l}\text { A. Girls with ASD } \\
(n=20)\end{array}$} & \multicolumn{2}{|c|}{$\begin{array}{l}\text { B. Boys with ASD } \\
(n=20)\end{array}$} & \multicolumn{2}{|c|}{$\begin{array}{l}\text { C. TYP girls } \\
(n=19)\end{array}$} & \multicolumn{3}{|c|}{ D. TYP boys $(n=17)$} & \multirow[t]{2}{*}{ Group differences ${ }^{\mathrm{a}}$} \\
\hline & $M$ & SD & $M$ & SD & $M$ & SD & $M$ & SD & $p$ & \\
\hline Age (years) & 12.00 & 3.42 & 12.45 & 3.72 & 12.53 & 3.32 & 11.47 & 2.37 & $n s$ & - \\
\hline FSIQ & 104.20 & 15.29 & 103.95 & 16.87 & 113.26 & 10.23 & 121.65 & 11.01 & $<.001$ & $\mathrm{C}, \mathrm{D}>\mathrm{A}, \mathrm{B}$ \\
\hline VIQ & 108.75 & 15.12 & 103.05 & 16.00 & 113.68 & 12.64 & 122.12 & 12.12 & .001 & $\mathrm{C}>\mathrm{B} ; \mathrm{D}>\mathrm{A}, \mathrm{B}$ \\
\hline PIQ & 99.00 & 17.10 & 107.10 & 16.93 & 109.89 & 11.48 & 116.65 & 11.98 & .006 & $\mathrm{C}, \mathrm{D}>\mathrm{A}$ \\
\hline ADOS total & 10.75 & 2.73 & 10.50 & 3.95 & - & - & - & - & $n s$ & - \\
\hline ADOS communication & 2.95 & .94 & 3.75 & 2.07 & - & - & - & - & $n s$ & - \\
\hline ADOS social & 7.80 & 2.35 & 7.30 & 2.49 & - & - & - & - & $n s$ & - \\
\hline SCQ total & 21.95 & 6.19 & 23.05 & 6.64 & 1.58 & 1.92 & 2.00 & 2.12 & $<.001$ & $\mathrm{~A}, \mathrm{~B}>\mathrm{C}, \mathrm{D}$ \\
\hline
\end{tabular}

$A S D$ autism spectrum disorder, TYP typically developing, FSIQ full scale IQ, VIQ verbal IQ, PIQ performance IQ, ADOS autism diagnostic observation schedule, SCQ Social Communication Questionnaire

${ }^{\mathrm{a}} \mathrm{A}=$ Girls with ASD, B = boys with ASD, C = TYP girls, D = TYP boys

TYP girls, 8 for TYP boys). The decision to include individuals with HFA, AS, and PDD-NOS was made based on studies showing that it is difficult to reliably distinguish between them (Macintosh and Dissanayake 2004; Ozonoff and Griffith 2000). Participant characteristics are displayed in Table 1.

Participants were recruited from local physicians, psychologists, speech-language pathologists, occupational therapists, advocacy groups, regional centers (state centers for the developmentally disabled), ASD support groups, and the MIND Institute's Subject Tracking System, which includes children with developmental disorders as well as TYP children. Participants with ASD were required to meet criteria for Autistic Disorder, AS, or PDD-NOS according to DSM-IV-TR criteria (American Psychiatric Association 2000). Based on parent report, participants could not have a diagnosis of depression, anxiety disorders, Attention-Deficit/Hyperactivity Disorder (ADHD), Fragile X, Tourette's, or seizure disorders. Diagnosed learning disabilities were not exclusionary. Participants completed all measures during a single visit. All procedures were approved by the UC Davis Medical Center Institutional Review Board.

\section{Qualification Measures}

Wechsler Abbreviated Scale of Intelligence (WASI; Wechsler 1999). The four-subtest (Vocabulary, Block Design, Similarities, Matrix Reasoning) version of the WASI was used to provide a short and reliable assessment of intelligence. It produces Verbal (VIQ), Performance (PIQ), and Full Scale IQ (FSIQ) Standard Scores with means of 100 and $S D$ s of 15 . The WASI is nationally standardized and has strong psychometric properties. Testretest reliability for IQ scales ranges from .88 to .93. Participants were required to have FSIQ scores above 75.
Scores ranged from 76 to 145 in the ASD groups and 98-139 in the TYP groups.

Autism Diagnostic Observation Schedule-Generic (ADOS-G; Lord et al. 2000). To confirm diagnosis, participants with ASD were administered module 3 or 4 of the ADOS-G by a clinical psychologist. The ADOS-G is a semi-structured protocol that offers standardized observation of social-communication behavior. Each module has approximately 10 standardized interactional "presses." Participants are rated based on their responses and scored for communication, reciprocal social behavior, and repetitive behaviors and stereotyped interest patterns. An algorithm score that combines the communication and reciprocal social interaction domains is the basis for diagnostic classification. Algorithm scores ranged from 7 to 18 in girls with ASD and 7-22 in boys with ASD.

Social Communication Questionnaire (SCQ; Rutter et al. 2003). Participants' parents completed the SCQ, a 40-item questionnaire to evaluate communication and social skills. It contains parallel questions to those on the Autism Diagnostic Interview-Revised (Lord et al. 1994), the gold standard parent-report diagnostic measure, in a briefer format. Berument et al. (1999) reported that a cutoff of 15 gave sensitivity of .96 and specificity of .80 for autism versus other diagnoses. Children with ASD were required to score $\geq 15$ while TYP groups were required to score $<11$. Scores ranged from 15 to 37 in the ASD groups and $0-8$ in the TYP groups.

\section{Autism Symptom Measures}

The measures used to assess autism symptoms included the Social Responsiveness Scale (SRS; Constantino 2002), Children's Communication Checklist-2nd Edition (CCC-2; Bishop 2003), and the Repetitive Behavior Scale-Revised 
(RBS-R; Bodfish et al. 1999). Subscale and total scores were used as dependent variables in analyses; however, we emphasize the relative importance of total versus subscale scores given that subscale scores consist of fewer items and thus are less reliable than total scores.

SRS (Constantino 2002) The SRS is a 65-item scale used to assess autism symptom severity. Subscales include: Social awareness (ability to pick up on social cues), social cognition (interpretation of social cues), social communication (expressive social communication), social motivation (how motivated the child is to engage in social behavior), and autistic mannerisms (stereotyped behaviors). The SRS has acceptable levels of internal consistency (.93-.97) and test-retest reliability (.77-.85). We obtained parent-reported SRS scores. A $T$-score of 60 constitutes a clinical cutoff.

CCC-2 (Bishop 2003) The CCC-2 is a 70-item parentreported measure of communication. We examined the General Communication Composite (GCC), Social Interaction Deviance Index (SIDI), and subscale scores. The GCC measures structural language skills and is used to identify children who have communication problems. The SIDI assesses pragmatic abilities (e.g., nonverbal communication, scripted language, use of humor and irony) and is used to identify children who may have ASD (scores $\leq$ -11 ). Subscale reliability estimates range from .66 to .80 in TYP children.

$R B S-R$ (Bodfish et al. 1999) The RBS-R is a 43-item parent-reported measure assessing restricted and repetitive behavior. Subscales include the following: Stereotyped behavior, self-injurious behavior, compulsive behavior, ritualistic behavior, sameness behavior, and restricted behavior, and an overall score. The RBS-R has acceptable levels of inter-rater reliability (.88), test-retest reliability (.71), and internal consistency (.78 to .91).

\section{Internalizing Psychopathology Measures}

The following measures were used to assess internalizing psychopathology, and constitute relevant dependent variables: Behavior Assessment System for Children-2nd Edition (BASC2 subscales: Reynolds and Kamphaus 2004) and Children's Depression Inventory (CDI; Kovacs 1992).

BASC2 (Reynolds and Kamphaus 2004) The BASC2 is used to evaluate adaptive and problem behaviors of children ages 2-25, and has exhibited acceptable levels of test-retest reliability (.76 to .84 ) and internal consistency (.80 to .87 ). We utilized raw parent-reported scores from the depression, anxiety, and internalizing problems (a composite of anxiety, depression, and somatization items) scales. $T$-scores above 60 fall within the clinical range.

CDI (Kovacs 1992) The CDI was used to assess depression levels in children 7-17. It is a self-report inventory with 27 items, each scored on a 3-point metric. Items describe different aspects of child mood, interpersonal problems, feelings of effectiveness, physical symptoms, and self-esteem. It has acceptable levels of internal consistency (.86), test-retest reliability (.54 to .56), and discriminant validity, with sensitivity of $80 \%$ and specificity of $84 \%$ in distinguishing children with depression from those without. A raw score of 19 constitutes a clinical cutoff. Seven participants (two girls with ASD, three boys with ASD, two TYP girls) were older than the age-norms cutoff. However, we utilized raw scores, and results did not differ when excluding these participants.

\section{Data Analytic Plan}

The two ASD groups were well matched on IQ and age. However, as shown in Table 1, there were significant differences between ASD and TYP groups on some IQ measures $(p s<.05)$. Girls and boys with ASD did not differ on the ADOS-G algorithm score and its subscales, although in terms of comparing autism symptom levels, the focus is on the examination of measures of autism symptoms that were not used as the basis for diagnosis (i.e., SRS, CCC-2, RBS-R).

Because variable scores for a particular measure are likely correlated, a multivariate analysis of variance (MANOVA) would have been a preferable analytical approach. However, because the distributions of variable scores strongly deviated from a multivariate normal distribution, significance determinations based on a MANOVA would not have been reliable. Therefore, we used univariate methods to identify variables that differed significantly among the four groups and adjusted $p$-values to account for multiple hypothesis testing within a measure.

IQ scores differed significantly among some groups (Table 1). To account for the potential confounding effect of IQ, we regressed variable scores on IQ and used the residuals for analysis. We examined differences among the four groups in autism symptom and internalizing psychopathology variables using Kruskal-Wallis tests. We then used Mann-Whitney $U$ tests to examine four planned contrasts: (1) girls and boys with ASD, (2) girls with ASD and TYP girls, (3) boys with ASD and TYP boys, and (4) TYP girls and boys. Next, we applied this procedure to internalizing psychopathology variables in adolescents only. Within each measure, a Bonferroni correction was used to control the Type I error rate at .05 across the analyses of several scores within the measure. A second Bonferroni adjustment was applied to the planned contrasts; thus maintaining the Type I error rate for a measure at .05 across all tests and contrasts. Significance thresholds are noted for each variable and follow-up comparisons. 
Sex-norms were available for some measures (SRS, BASC-2, CDI). We reasoned that normed scores could mask potential sex differences, given that norms may be quite different for males and females. Raw scores provide, by definition, a clearer view of sex effects on a given scale. Thus, if a measure included sex-specific norms, analyses examined both normed and raw scores. Results remained essentially the same with normed versus raw scores; results from raw scores are presented.

\section{Results}

\section{Autism Symptoms}

We first examined raw SRS scores. Means, SDs, and effect sizes (Cohen's $d$ ) are listed in Table 2. With six SRS variables, the Bonferroni-adjusted alpha was .0083 for determining significance. There was a main effect of group on SRS total scores, $\chi^{2}=33.36$; social awareness, $\chi^{2}=36.25$; social cognition, $F(3,76)=31.81$; social communication, $\chi^{2}=35.11$; social motivation, $\chi^{2}=25.96$; and autistic mannerisms, $\chi^{2}=34.77, d f=3, N=76$ for all. Follow-up comparisons using an adjusted alpha level of $.0021(.0083 / 4)$ revealed that there were no differences between boys and girls with ASD on any SRS variables. TYP girls had lower scores than girls with ASD on all SRS subscales $(p s=.001)$. There were no differences between TYP boys and boys with ASD that withstood the Bonferroni correction. Finally, TYP girls did not differ from TYP boys.

Next, we examined age-normed CCC-2 scores (Table 2). With 12 CCC-2 variables, a Bonferroni-adjusted alpha level of .0042 was employed. There was a main effect of group on both composite scales: GCC, $\chi^{2}=39.26 ; \quad$ and SIDI, $\chi^{2}=25.28, \quad d f=3, \quad N=76$, $p<.001$ for both. There was also a main effect of group on all subscales: Speech, $\chi^{2}=21.15$; syntax, $\chi^{2}=21.37$; semantics, $\chi^{2}=32.23$; coherence, $\chi^{2}=38.03$; initiation, $\chi^{2}=47.90 ; \quad$ scripted language, $\chi^{2}=46.21 ;$ context, $\chi^{2}=41.68$; nonverbal communication, $\chi^{2}=48.17$; social relations, $\chi^{2}=49.26$; and interests, $\chi^{2}=49.88, d f=3$, $N=76$ for all. Follow-up comparisons using an adjusted alpha level of $.0011(.0042 / 4)$ revealed that boys and girls with ASD did not differ on any variable. TYP girls had higher (less impaired) scores than girls with ASD on all variables $(p s=.001)$. TYP boys also had higher scores than boys with ASD on all variables $(p s=.001)$. TYP girls and TYP boys did not differ.

Finally, we examined seven RBS-R scores (Table 3) using a Bonferroni-adjusted alpha level of .0071. Because of a data collection problem, scores were missing for five girls with ASD and five TYP girls. There was a main effect of group on all RBS-R scores: Stereotyped behavior, $\chi^{2}=38.48$; self-injurious behavior, $\chi^{2}=25.80$; compulsive behavior, $\chi^{2}=32.25$; ritualistic behavior, $\chi^{2}=39.65$; sameness behavior, $\chi^{2}=45.93$; restricted interests, $\chi^{2}=43.34 ;$ and overall scores, $\chi^{2}=43.40, d f=3$, $N=66$ for all. Follow-up comparisons using an adjusted alpha level of .0018 (.0071/4) revealed that boys and girls with ASD did not differ on any subscale, although the results are suggestive of higher scores in boys with ASD on the restricted interests subscale, $U=77.50, z=-2.43$, $p=.015$ without such stringent corrections for multiple comparisons. Girls with ASD had higher scores than TYP girls on all subscales $(p s<.001)$ with the exception of the compulsive behavior subscale. Boys with ASD had higher scores than TYP boys ( $p$ s $=.001$ ), but TYP girls and TYP boys did not differ.

\section{Internalizing Psychopathology}

Raw scores from the internalizing problems, depression, and anxiety scales of BASC-2 were examined first across the entire sample (Table 4). There was a main effect of group on all BASC2 subscales, using a Bonferroni-adjusted alpha level of .0167 for the three BASC2 variables: Anxiety, $\chi^{2}=18.07 ;$ depression, $\chi^{2}=38.80$ and internalizing scores, $\chi^{2}=32.52, d f=3, N=75$ for all. Follow-up comparisons using an adjusted alpha level of .0042 (.0167/4) revealed that boys and girls with ASD did not differ on these variables. Girls with ASD had higher scores than TYP girls on all variables $(p s<.001)$. Boys with ASD had higher depression scores than TYP boys $(p<.001)$ but did not differ on anxiety or internalizing scores. TYP boys and TYP girls did not differ from each other on any BASC2 variables.

We next examined raw scores from child-reported CDI across the entire sample using an alpha level of .05 . There was a main effect of group on the CDI, $\chi^{2}(3$, $N=76)=20.35$. Follow-up comparisons using an alpha level of .0125 (.05/4) revealed that girls and boys with ASD did not differ, whereas girls with ASD had higher scores than TYP girls $(p<.001)$. Boys with ASD and TYP boys did not differ, nor did TYP girls and TYP boys. It is noteworthy that five of the seven scores that fell in the "at risk" or "significant" range for depression on the CDI belonged to girls with ASD, totaling $26 \%$ of this group. The other two scores belonged to TYP boys, equating to $12 \%$ of this group. A chi square test indicated that the percentage of participants who fell in the "at risk" or "significant" range for depression significantly differed by group, $\chi^{2}(3, N=76)=10.05, p<.02$.

We also examined raw scores from internalizing psychopathology variables in adolescents alone (ages 12-18, Table 5). There was a main effect of group on the three 


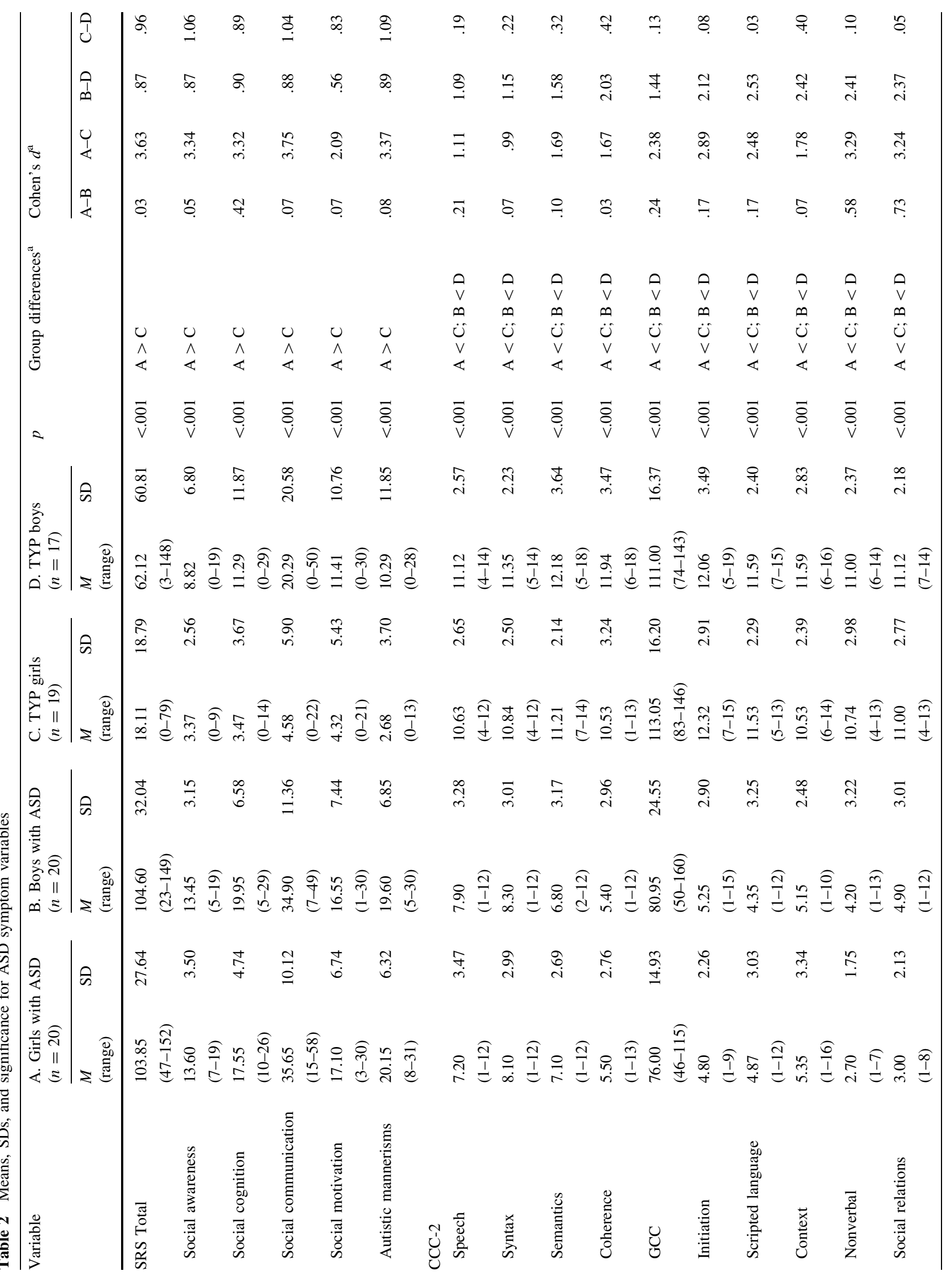




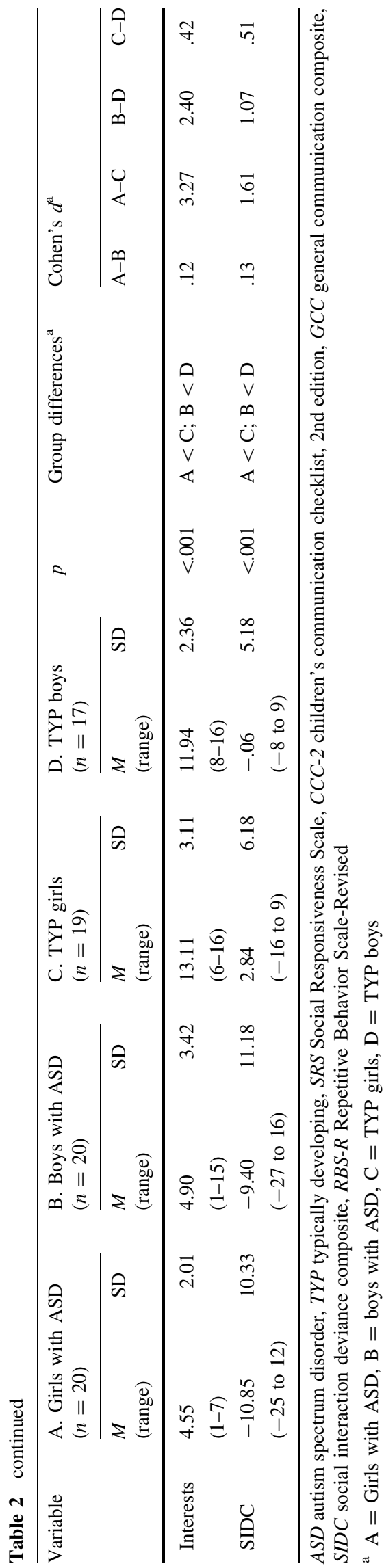

parent-reported BASC2 subscales: anxiety, $\chi^{2}=12.28$; depression, $\chi^{2}=20.86$; and internalizing, $\chi^{2}=17.98$, $d f=3, N=37$ for all, using a Bonferroni-adjusted alpha level of .0167. There was also a main effect of group on selfreported CDI scores using an alpha level of $.05, \chi^{2}(3$, $N=37)=12.73$. Follow-up comparisons with BASC2 scores using an alpha level of .0042 (.0167/4) revealed marginally significantly higher anxiety scores in adolescent females with ASD than males with $\mathrm{ASD}, U=15.50, z=$ $-2.62, p=.009$. These two groups did not differ in depression scores, but females with ASD had significantly higher internalizing scores than males with $\operatorname{ASD}(p<.001)$. Females with ASD also had higher scores than TYP females on anxiety, depression, and internalizing $(p s<.001)$. Males with ASD and TYP males did not differ on anxiety or internalizing scores, but males with ASD had marginally significantly higher depression scores than TYP males $(p=.011)$. TYP females and males did not differ on any scale. For CDI scores, there was a main effect of group using an alpha level of $.05, \chi^{2}(3, N=37)=12.73$. Using an alpha level of $.0125(.05 / 4)$ for follow-up comparisons, there was no difference between adolescent males and females with ASD. Females with ASD had higher scores than TYP females $(p=.01)$. Males with ASD did not differ from TYP males nor did TYP males differ from TYP females.

\section{Discussion}

Our primary aims were (1) to determine whether girls with ASD show fewer social and language ASD-related symptoms than boys with ASD, and whether boys with ASD exhibit higher levels of restricted and repetitive behaviors than all other groups; (2) to assess whether girls with ASD are more impaired than TYP girls in terms of social and language abilities; and (3) to examine whether girls with ASD show elevated levels of internalizing symptoms compared to all other groups. We found that ASD symptom profiles were very similar in boys and girls with ASD, and that girls with ASD differed markedly from TYP girls on symptom measures that were not used as a basis for diagnosis, indicating that girls with ASD did not resemble TYP girls in terms of language and social abilities. Differences also emerged with respect to internalizing psychopathology as adolescent girls with ASD evidenced significant internalizing symptoms compared to boys with ASD and TYP girls.

There were marginally significant differences in the area of restricted interests, which was consistent with some previous research that has found that these interests (an aspect of repetitive behaviors) are more pronounced in boys with ASD than girls with ASD (e.g., Hartley and 
Table 3 Means, SDs, and significance for RBS-R variables

\begin{tabular}{|c|c|c|c|c|c|c|c|c|c|c|c|c|c|c|}
\hline \multirow[t]{2}{*}{ Variable } & \multicolumn{2}{|c|}{$\begin{array}{l}\text { A. Girls with ASD } \\
(n=15)\end{array}$} & \multicolumn{2}{|c|}{$\begin{array}{l}\text { B. Boys with ASD } \\
(n=20)\end{array}$} & \multicolumn{2}{|c|}{$\begin{array}{l}\text { C. TYP girls } \\
(n=14)\end{array}$} & \multicolumn{3}{|c|}{$\begin{array}{l}\text { D. TYP boys } \\
(n=17)\end{array}$} & \multirow[t]{2}{*}{$\begin{array}{l}\text { Group } \\
\text { differences }^{\mathrm{a}}\end{array}$} & \multicolumn{4}{|c|}{ Cohen's $d^{\mathrm{a}}$} \\
\hline & $\begin{array}{l}M \\
\text { (range) }\end{array}$ & SD & $\begin{array}{l}M \\
\text { (range) }\end{array}$ & SD & $\begin{array}{l}M \\
\text { (range) }\end{array}$ & SD & $\begin{array}{l}M \\
\text { (range) }\end{array}$ & SD & $p$ & & A-B & $\mathrm{A}-\mathrm{C}$ & B-D & C-D \\
\hline RBS-R overall & $\begin{array}{l}2.47 \\
(6-72)\end{array}$ & 1.77 & $\begin{array}{l}5.00 \\
(0-91)\end{array}$ & 3.16 & $\begin{array}{l}.00 \\
(0-18)\end{array}$ & .00 & $\begin{array}{l}.41 \\
(0-11)\end{array}$ & 1.23 & $<.001$ & $\mathrm{~A}>\mathrm{C} ; \mathrm{B}>\mathrm{D}$ & .51 & 1.97 & 1.91 & .47 \\
\hline Stereotyped & $\begin{array}{l}4.27 \\
(0-13)\end{array}$ & 3.63 & $\begin{array}{l}5.20 \\
(0-15)\end{array}$ & 3.83 & $\begin{array}{l}.00 \\
(0)\end{array}$ & .00 & $\begin{array}{l}.71 \\
(0-6)\end{array}$ & 1.83 & $<.001$ & $\mathrm{~A}>\mathrm{C} ; \mathrm{B}>\mathrm{D}$ & .25 & 1.66 & 1.50 & .55 \\
\hline Self-injurious & $\begin{array}{l}2.53 \\
(0-6)\end{array}$ & 2.07 & $\begin{array}{l}3.75 \\
(0-12)\end{array}$ & 4.14 & $\begin{array}{l}.00 \\
(0)\end{array}$ & .00 & $\begin{array}{l}.41 \\
(0-4)\end{array}$ & 1.06 & $<.001$ & $\mathrm{~A}>\mathrm{C} ; \mathrm{B}>\mathrm{D}$ & .37 & 1.73 & 1.11 & .55 \\
\hline Compulsive & $\begin{array}{l}4.40 \\
(0-18)\end{array}$ & 5.03 & $\begin{array}{l}6.80 \\
(0-18)\end{array}$ & 4.99 & $\begin{array}{l}.93 \\
(0-5)\end{array}$ & 1.73 & $\begin{array}{l}.29 \\
(0-3)\end{array}$ & .77 & $<.001$ & $\mathrm{~B}>\mathrm{D}$ & .48 & .92 & 1.82 & .48 \\
\hline Ritualistic & $\begin{array}{l}4.93 \\
(0-14)\end{array}$ & 4.03 & $\begin{array}{l}7.00 \\
(0-17)\end{array}$ & 5.42 & $\begin{array}{l}.36 \\
(0-5)\end{array}$ & 1.34 & $\begin{array}{l}.29 \\
(0-2)\end{array}$ & .69 & $<.001$ & $\mathrm{~A}>\mathrm{C} ; \mathrm{B}>\mathrm{D}$ & .43 & 1.52 & 1.74 & .07 \\
\hline Sameness & $\begin{array}{l}9.13 \\
(2-23)\end{array}$ & 6.15 & $\begin{array}{l}11.20 \\
(0-31)\end{array}$ & 8.31 & $\begin{array}{l}.71 \\
(0-8)\end{array}$ & 2.13 & $\begin{array}{l}.24 \\
(0-2)\end{array}$ & .56 & $<.001$ & $\mathrm{~A}>\mathrm{C} ; \mathrm{B}>\mathrm{D}$ & .28 & 1.83 & 1.86 & .30 \\
\hline Restricted interests & $\begin{array}{l}2.47 \\
(0-6)\end{array}$ & 1.77 & $\begin{array}{l}5.00 \\
(0-11)\end{array}$ & 3.16 & $\begin{array}{l}.00 \\
(0)\end{array}$ & .00 & $\begin{array}{l}.41 \\
(0-5)\end{array}$ & 1.23 & $<.001$ & $\mathrm{~A}>\mathrm{C} ; \mathrm{B}>\mathrm{D}$ & .99 & 1.97 & 1.91 & .47 \\
\hline
\end{tabular}

$A S D$ autism spectrum disorder, TYP typically developing, $R B S-R$ Repetitive Behavior Scale-Revised

${ }^{\mathrm{a}} \mathrm{A}=$ Girls with ASD, B = boys with ASD, $\mathrm{C}=$ TYP girls, $\mathrm{D}=$ TYP boys

Table 4 Means, SDs, and significance for internalizing psychopathology variables

\begin{tabular}{|c|c|c|c|c|c|c|c|c|c|c|c|c|c|c|}
\hline \multirow[t]{2}{*}{ Variable } & \multicolumn{2}{|c|}{$\begin{array}{l}\text { A. Girls with ASD } \\
(n=20)\end{array}$} & \multicolumn{2}{|c|}{$\begin{array}{l}\text { B. Boys with ASD } \\
(n=20)\end{array}$} & \multicolumn{2}{|c|}{$\begin{array}{l}\text { C. TYP girls } \\
(n=19)\end{array}$} & \multicolumn{3}{|c|}{$\begin{array}{l}\text { D. TYP boys } \\
(n=17)\end{array}$} & \multirow[t]{2}{*}{$\begin{array}{l}\text { Group } \\
\text { differences }^{\mathrm{a}}\end{array}$} & \multicolumn{4}{|c|}{ Cohen's $d^{\mathrm{a}}$} \\
\hline & $\begin{array}{l}M \\
\text { (range) }\end{array}$ & SD & $\begin{array}{l}M \\
\text { (range) }\end{array}$ & SD & $\begin{array}{l}M \\
\text { (range) }\end{array}$ & SD & $\begin{array}{l}M \\
\text { (range) }\end{array}$ & SD & $p$ & & A-B & $\mathrm{A}-\mathrm{C}$ & B-D & $\mathrm{C}-\mathrm{D}$ \\
\hline \multicolumn{15}{|l|}{$\mathrm{BASC} 2^{\mathrm{b}}$} \\
\hline Anxiety & $\begin{array}{l}17.45 \\
(6-26)\end{array}$ & 6.15 & $\begin{array}{l}15.74 \\
(3-39)\end{array}$ & 9.49 & $\begin{array}{l}9.58 \\
(0-24)\end{array}$ & 5.81 & $\begin{array}{l}9.47 \\
(0-25)\end{array}$ & 6.08 & $<.001$ & $\mathrm{~A}>\mathrm{C} ; \mathrm{B}>\mathrm{D}$ & .21 & 1.32 & .79 & .02 \\
\hline Depression & $\begin{array}{l}17.15 \\
(6-26)\end{array}$ & 6.93 & $\begin{array}{l}13.00 \\
(2-31)\end{array}$ & 8.99 & $\begin{array}{l}3.79 \\
(0-10)\end{array}$ & 2.78 & $\begin{array}{l}4.29 \\
(1-16)\end{array}$ & 4.21 & $<.001$ & $\mathrm{~A}>\mathrm{C} ; \mathrm{B}>\mathrm{D}$ & .52 & 2.53 & 1.24 & .14 \\
\hline Internalizing & $\begin{array}{l}189.85 \\
(126-226)\end{array}$ & 28.91 & $\begin{array}{l}174.32 \\
(120-269)\end{array}$ & 40.00 & $\begin{array}{l}136.95 \\
(101-179)\end{array}$ & 20.15 & $\begin{array}{l}142.53 \\
(109-184)\end{array}$ & 17.84 & $<.001$ & $\mathrm{~A}>\mathrm{C} ; \mathrm{B}>\mathrm{D}$ & .45 & 2.12 & 1.03 & .29 \\
\hline CDI & $\begin{array}{l}11.95 \\
(0-33)\end{array}$ & 7.83 & $\begin{array}{l}9.80 \\
(1-17)\end{array}$ & 5.27 & $\begin{array}{l}3.47 \\
(0-17)\end{array}$ & 4.01 & $\begin{array}{l}5.65 \\
(0-17)\end{array}$ & 5.41 & $<.001$ & $\mathrm{~A}>\mathrm{C}$ & .32 & 1.36 & .78 & .46 \\
\hline
\end{tabular}

$A S D$ autism spectrum disorder; TYP typically developing, BASC2 behavior assessment system for children, 2nd edition, $C D I$ children's depression inventory

${ }^{\text {a }} \mathrm{A}=$ Girls with ASD, B = boys with ASD, C = TYP girls, D = TYP boys

b For all BASC2 variables, $n=19$ for boys with ASD

Sikora 2009; McLennan et al. 1993). Differences in repetitive behaviors may be linked to variations in neuropeptides such as oxytocin and vasopressin (Carter 2007; Hollander et al. 2003; Insel et al. 1999), and small studies have shown that infusions of oxytocin reduce these behaviors in adult males with ASD (Hollander et al. 2003). However, it remains possible that a gender bias exists on the RBS-R restricted interests subscale in particular, which refers to objects such as trains, dinosaurs, and toy carstraditionally male interests. Clinical lore suggests that restricted interests of girls with ASD may be different and it remains possible that parents of girls with ASD might report higher levels of restricted interests if examples on this parent-report measure included a wider range of 
Table 5 Means, SDs, and significance for adolescent age and internalizing psychopathology variables

\begin{tabular}{|c|c|c|c|c|c|c|c|c|c|c|c|c|c|c|}
\hline \multirow[t]{2}{*}{ Variable } & \multicolumn{2}{|c|}{$\begin{array}{l}\text { A. Girls with ASD } \\
(n=10)\end{array}$} & \multicolumn{2}{|c|}{$\begin{array}{l}\text { B. Boys with ASD } \\
(n=10)\end{array}$} & \multicolumn{2}{|c|}{$\begin{array}{l}\text { C. TYP girls } \\
(n=9)\end{array}$} & \multicolumn{3}{|c|}{$\begin{array}{l}\text { D. TYP boys } \\
(n=8)\end{array}$} & \multirow[t]{2}{*}{$\begin{array}{l}\text { Group } \\
\text { differences }{ }^{a}\end{array}$} & \multicolumn{4}{|c|}{ Cohen's $d^{\mathrm{a}}$} \\
\hline & $\begin{array}{l}M \\
\text { (range) }\end{array}$ & SD & $\begin{array}{l}M \\
\text { (range) }\end{array}$ & SD & $\begin{array}{l}M \\
\text { (range) }\end{array}$ & SD & $\begin{array}{l}M \\
\text { (range) }\end{array}$ & SD & $p$ & & $\mathrm{~A}-\mathrm{B}$ & $\mathrm{A}-\mathrm{C}$ & B-D & $\mathrm{C}-\mathrm{D}$ \\
\hline Age & $\begin{array}{l}14.90 \\
(12-18)\end{array}$ & 2.13 & $\begin{array}{l}15.70 \\
(12-18)\end{array}$ & 2.06 & $\begin{array}{l}15.56 \\
(12-18)\end{array}$ & 2.07 & $\begin{array}{l}13.38 \\
(12-17)\end{array}$ & 1.85 & $n s$ & & .38 & .31 & .07 & 1.11 \\
\hline \multicolumn{15}{|l|}{ BASC2 } \\
\hline Anxiety & $\begin{array}{l}18.00 \\
(8-26)\end{array}$ & 5.85 & $\begin{array}{l}10.40 \\
(3-20)\end{array}$ & 6.06 & $\begin{array}{l}8.78 \\
(1-14)\end{array}$ & 4.24 & $\begin{array}{l}8.75 \\
(1-16)\end{array}$ & 4.83 & .006 & $\mathrm{~A}>\mathrm{C}$ & 1.28 & 1.08 & .30 & .01 \\
\hline Depression & $\begin{array}{l}16.80 \\
(7-25)\end{array}$ & 7.45 & $\begin{array}{l}9.50 \\
(2-21)\end{array}$ & 6.79 & $\begin{array}{l}3.22 \\
(0-7)\end{array}$ & 2.28 & $\begin{array}{l}3.25 \\
(1-12)\end{array}$ & 3.73 & $<.001$ & $\mathrm{~A}>\mathrm{C}$ & 1.02 & 2.47 & 1.14 & .01 \\
\hline Internalizing & $\begin{array}{l}200.80 \\
(151-226)\end{array}$ & 25.64 & $\begin{array}{l}155.90 \\
(120-209)\end{array}$ & 28.60 & $\begin{array}{l}137.33 \\
(113-170)\end{array}$ & 19.47 & $\begin{array}{l}141.75 \\
(109-184)\end{array}$ & 21.82 & $<.001$ & $\mathrm{~A}>\mathrm{B}, \mathrm{C}$ & 1.65 & 2.79 & .56 & .21 \\
\hline CDI & $\begin{array}{l}11.50 \\
(0-33)\end{array}$ & 9.18 & $\begin{array}{l}8.90 \\
(2-15)\end{array}$ & 4.86 & $\begin{array}{l}2.33 \\
(0-6)\end{array}$ & 2.24 & $\begin{array}{l}4.25 \\
(1-10)\end{array}$ & 3.11 & .005 & $\mathrm{~A}>\mathrm{C}$ & .35 & 1.37 & 1.14 & .71 \\
\hline
\end{tabular}

$A S D$ autism spectrum disorder; TYP typically developing, BASC2 behavior assessment system for children, 2nd edition, $C D I$ children's depression inventory

${ }^{\mathrm{a}} \mathrm{A}=$ Girls with ASD, B = boys with ASD, C = TYP girls, D = TYP boys

choices. This is consistent with the assertion that sex-specific diagnostic criteria for neuropsychiatric disorders would be more precise and useful (see Hartung and Widiger 1998).

As predicted, girls with ASD appeared to be at greater risk for internalizing psychopathology than boys with ASD and TYP girls. None of the boys with ASD or TYP girls fell within the clinical range on the self-report CDI, compared with $26 \%$ of the girls with ASD. In adolescence, girls with ASD had significantly higher parent-reported internalizing scores than boys with ASD and TYP girls. This contention is consistent with work indicating there are more internalizing problems in girls with ADHD than in boys with the disorder (Gershon 2002; Rucklidge and Tannock 2001) and comparison girls (Rucklidge and Tannock 2001), and is also consistent with the suggestion that being female and having a neurodevelopmental disorder may confer particularly high risk with regard to internalizing psychopathology.

Prior research indicates that TYP girls tend to express concern about others' feelings and interact in smaller, more intimate social groups (Maccoby 1998). Additionally, it has been shown that affiliative orientation intensifies in girls in adolescence (Larson and Richards 1989), and conversations become more interpersonally-focused (Raffaelli and Duckett 1989). These differences in basic social processes, along with dramatic social changes in adolescence, could reveal relative social skill deficits in girls with ASD and lead to greater isolation during this developmental period. It is also possible that emotion socialization plays a role given that girls are more likely to be encouraged to express their emotions-particularly fear and sadness - than boys (for a review, see Brody 2000), leading parents of girls with ASD to have more knowledge of their daughters' internal states than their sons'. Still, girls with ASD might be expected to do this less than TYP girls, yet they still exhibited more internalizing symptoms than TYP girls. Such hypotheses should be investigated further, due to their potential clinical significance.

Indeed, the clinical relevance of understanding elevated levels of internalizing symptoms in girls with ASD is high. Determining ways to best treat such symptoms in girls with ASD will be critical. Studies using cognitive-behavioral strategies to address anxiety in higher-functioning children with ASD have shown promise (Reaven et al. 2009; Wood et al. 2008). Little research has focused on using cognitive-behavioral methods to address depression in this population although such pursuits may be fruitful. Additionally, group-based social skills interventions that include components targeting emotion recognition, emotion regulation, and additional problem solving/coping strategies along with skills for developing more successful social relationships have been shown to have an effect on depression scores in boys with ASD and their parents (Solomon et al. 2004). Developing and implementing interventions-cognitive, behavioral, and psychotropicto address internalizing symptoms in this high risk population of girls with ASD could prove to have dramatic effects on adult outcomes that have been associated with adolescent depression, including risk for affective disorders, psychiatric hospitalization, and suicidal ideation (Colman et al. 2007). 
While the purpose of this investigation was not to address whether girls with ASD are under-diagnosed, we note the importance of this issue to the field. Furthermore, consistent with ADHD findings, boys and girls were similarly impaired as evidenced by comparable diagnostic and non-diagnostic ASD symptom scores. Research about sex differences in ADHD may be instructive. Although the belief that girls with ADHD are less symptomatic than boys was prevalent, large longitudinal studies of girls with ADHD have found this population to be significantly impaired (e.g., Hinshaw 2002; Hinshaw et al. 2006). As in our study, a meta-analysis by Gaub and Carlson (1997) found similar ADHD symptom profiles between boys with ADHD and clinic-referred girls with ADHD. However, they also found that non-referred girls displayed lower rates of ADHD behaviors. Similarly, it may be that only girls with substantial impairments in core ASD symptoms are referred, so that clinic samples mask sex differences in symptoms existing in the community. Population-based studies are needed to address these important questions. Given that our sample was clinic-referred, it is likely to have consisted of a more severely impaired group of girls and boys than would be found in the community, resulting in groups that were very similar in terms of ASD symptoms.

Limitations of the study include its small size and lack of perfect IQ matching. Additionally, we did not include an observer-report standardized assessment of comorbid psychopathology in either ASD or TYP participants, and the measures we did use were validated for TYP youth. Thus, it is not clear that the measures used in this study are accurately assessing internalizing symptoms in individuals with ASD. Unfortunately, no other assessment measures exist to specifically measure internalizing symptoms in ASD populations, and there may be high overlap between ASD-like traits and internalizing traits (Hallet et al. 2010). However, we still found that higher levels of internalizing symptoms were specific to adolescent girls with ASD and not boys with ASD, suggesting that these assessments of internalizing symptoms were not merely reflecting manifestations of ASD symptoms. Finally, although results of analyses were corrected for multiple comparisons, many variables were examined given our sample size, increasing the potential for Type II error. Thus, this study serves as an initial platform for future empirical investigations of the female ASD phenotype using multivariate strategies.

In conclusion, the study of girls with ASD represents an important area for future research. This group appears to be at enhanced risk for developing affective symptoms in adolescence, suggesting the potential need for screening and intervention. Also, the question of whether girls with ASD in the community are less impaired and/or underdetected relative to boys remains unanswered. Finally, while we addressed questions related to our specific hypotheses, we did not address the underlying neurobiological questions from which they were derived. Future studies should examine neuropeptide levels in TYP boys and girls and boys and girls with ASD, as well as the genetics of sex differences in the prevalence and expression of the male and female phenotypes of the disorders, and relate this information to observed behavioral differences. Both lines of research hold the potential to advance the study of the pathophysiology of ASD and to provide information relevant to treatment development.

Acknowledgments This work was supported by a K-08 Award from the National Institute of Mental Health (1-K-08 MH074967-01) and a Building Interdisciplinary Research Careers in Women's Health Award (K12 HD051958) funded by the National Institute of Child Health and Human Development (NICHD), Office of Research on Women's Health (ORWH), Office of Dietary Supplements (ODS), and the National Institute of Aging (NIA) to Marjorie Solomon. Statistical support was made possible by Grant Number UL1 RR024246 from the National Center for Research Resources (NCRR), a component of NIH and NIH Roadmap for Medical Research. Its contents are solely the responsibility of the authors and do not necessarily represent the official view of NCRR or NIH. Information on Re-engineering the Clinical Research Enterprise can be obtained from http://nihroadmap.nih.gov/clinicalresearch/overview-translational.asp.

Conflicts of interest The authors report no conflicts of interest related to this manuscript.

Open Access This article is distributed under the terms of the Creative Commons Attribution Noncommercial License which permits any noncommercial use, distribution, and reproduction in any medium, provided the original author(s) and source are credited.

\section{References}

American Psychiatric Association. (2000). Diagnostic and statistical manual of mental disorders - 4th edition text revised (4th ed.). Washington, DC: American Psychiatric Association.

Banach, R., Thompson, A., Szatmari, P., Goldberg, J., Tuff, L., Zwaigenbaum, L., et al. (2009). Brief report: Relationship between non-verbal IQ and gender in autism. Journal of Autism and Developmental Disorders, 39, 188-193.

Baron-Cohen, S., Knickmeyer, R. C., \& Belmonte, M. K. (2005). Sex differences in the brain: Implications for explaining autism. Science, 310, 819-823.

Berument, S. K., Rutter, M., Lord, C., Pickles, A., \& Bailey, A. (1999). Autism screening questionnaire: Diagnostic validity. British Journal of Psychiatry, 175, 444-451.

Bishop, D. (2003). Children's communication checklist (2nd ed.). San Antonio, TX: Pearson.

Bodfish, J. W., Symons, F. J., \& Lewis, M. H. (1999). The repetitive behavior scale-revised. Western Carolina Center Research Reports.

Brody, L. R. (2000). The socialization of gender differences in emotional expression: Display rules, infant temperament, and differentiation. In A. H. Fischer (Ed.), Gender and emotion: Social psychological perspectives (pp. 24-47). New York: Cambridge University Press.

Carter, C. S. (2007). Sex differences in oxytocin and vasopressin: Implications for autism spectrum disorders? Behavioural Brain Research, 176, 170-186. 
Carter, A. S., Black, D. O., Tewani, S., Connolly, C. E., Kadlec, M. B., \& Tager-Flusberg, H. (2007). Sex differences in toddlers with autism spectrum disorders. Journal of Autism and Developmental Disorders, 37, 86-97.

Centers for Disease Control. (2009). MMWR surveillance summary (Vol. 58, pp. 1-20).

Colman, I., Wadsworth, M. E. J., Croudace, T. J., \& Jones, P. B. (2007). Forty-year psychiatric outcomes following assessment for internalizing disorder in adolescence. American Journal of Psychiatry, 164, 126-133.

Constantino, J. N. (2002). The social responsiveness scale. Los Angeles, CA: Western Psychological Services.

Constantino, J. N., \& Todd, R. D. (2003). Autistic traits in the general population: A twin study. Archives in General Psychiatry, 60, 524-530.

Eme, R. F. (1992). Selective female affliction in the developmental disorders of childhood: A literature review. Journal of Clinical Child Psychology, 21, 354-364.

Fombonne, E. (2003). Epidemiological surveys of autism and other pervasive developmental disorders: An update. Journal of Autism and Developmental Disorders, 33, 365-382.

Gaub, M., \& Carlson, C. L. (1997). Gender differences in ADHD: A meta-analysis and critical review. Journal of the American Academy of Child and Adolescent Psychiatry, 36, 1036-1045.

Gershon, J. (2002). A meta-analytic review of gender differences in ADHD. Journal of Attention Disorders, 5, 143-154.

Hallet, V., Ronald, A., Rijsdijk, F., \& Happé, F. (2010). Association of autistic-like and internalizing traits during childhood: A longitudinal twin study. American Journal of Psychiatry, 167, 809-817.

Hartley, S.L., \& Sikora, D.M. (2009). Sex differences in autism spectrum disorder: An examination of developmental functioning, autistic symptoms, and coexisting behavior problems in toddlers. Journal of Autism and Developmental Disorders, $1715-1722$.

Hartung, C. M., \& Widiger, T. A. (1998). Differences in the diagnosis of mental disorders: Conclusions and controversies of the DSMIV. Psychological Bulletin, 123, 260-278.

Hinshaw, S. P. (2002). Preadolescent girls with attention-deficit/ hyperactivity disorder: I. Background characteristics, comorbidity, cognitive and social functioning, and parenting practices. Journal of Consulting and Clinical Psychology, 70, 1086-1098.

Hinshaw, S. P., Owens, E. B., Sami, N., \& Fargeon, S. (2006). Prospective follow-up of girls with attention-deficit/hyperactivity disorder into adolescence: Evidence for continuing cross- domain impairment. Journal of Consulting and Clinical Psychology, 74, 489-499.

Hollander, E., Novotny, S., Hanratty, M., Yaffe, R., DeCaria, C. M., Aronowitz, B. R., et al. (2003). Oxytocin infusion reduces repetitive behaviors in adults with autism spectrum disorders. Neuropsychopharmacology, 28, 193-198.

Holliday-Willey, L. (1999). Pretending to be normal: Living with Asperger's syndrome. Philadelphia: Jessica Kingsley.

Holtmann, M., Bölte, S., \& Poustka, F. (2007). Autism spectrum disorders: Sex differences in autistic behaviour domains and coexisting psychopathology. Developmental Medicine and Child Neurology, 49, 361-366.

Insel, T. R., O’Brien, D. J., \& Leckman, J. F. (1999). Oxytocin, vasopressin, and autism: Is there a connection? Biological Psychiatry, 45, 145-157.

Kim, J. A., Szatmari, P., Bryson, S. E., Streiner, D. L., \& Wilson, F. J. (2000). The prevalence of anxiety and mood problems among children with autism and Asperger syndrome. Autism, 4, 117-132.

Koenig, K., \& Tsatsanis, K. (2005). Pervasive developmental disorders in girls. In D. Bell-Dolan, S. Foster, \& E. J. Mash
(Eds.), Behavioral and emotional problems in girls. New York: Kluwer Academic/Plenum.

Kovacs, M. (1992). Children's depression inventory manual. North Tonawanda, NY: Multi- Health Systems, Inc.

Lainhart, J. E., \& Folstein, S. E. (1994). Affective disorders in people with autism. Journal of Autism and Developmental Disorders, 24, 587-601.

Larson, R., \& Richards, M. H. (1989). Introduction: the changing life space of early adolescence. Journal of Youth and Adolescence, 18, 501-509.

Lord, C., Risi, S., Lambrecht, L., Cook, E. H., Leventhal, B. L., \& DiLavore, P. C. (2000). The autism diagnostic observation schedule-generic: A standard measure of social and communication deficits associated with the spectrum of autism. Journal of Autism and Developmental Disorders, 30, 205-223.

Lord, C., Rutter, M., \& LeCouteur, A. (1994). Autism diagnostic interview-revised: A revised version of a diagnostic interview for caregivers of individuals with possible pervasive developmental disorders. Journal of Autism and Developmental Disorders, 24, 659-685.

Lord, C., Schopler, E., \& Revicki, D. (1982). Sex differences in autism. Journal of Autism and Developmental Disorders, 12, 317-330.

Maccoby, E. E. (1998). The two sexes: Growing up apart, coming together. Cambridge, MA: Harvard University Press.

Macintosh, K. E., \& Dissanayake, C. (2004). Annotation: The similarities and differences between autistic disorder and Asperger's disorder: A review of the empirical evidence. Journal of Child Psychology and Psychiatry and Allied Disciplines, 45, 421-434.

Mazefsky, C. A., Conner, C. M., \& Oswald, D. P. (2010). Association between depression and anxiety in high-functioning children with autism spectrum disorders and maternal mood symptoms. Autism Research, 3, 120-127.

McLennan, J. D., Lord, C., \& Schopler, E. (1993). Sex differences in higher functioning people with autism. Journal of Autism and Developmental Disorders, 23, 217-227.

Nolen-Hoeksema, S., \& Girgus, J. S. (1994). The emergence of gender differences in depression during adolescence. Psychological Bulletin, 115, 424-443.

Ozonoff, S., \& Griffith, E. M. (2000). Neuropsychological function and the external validity of Asperger syndrome. In A. Klin, F. R. Volkmar, \& S. S. Sparrow (Eds.), Asperger syndrome. New York: Guilford Press.

Pilowsky, T., Yirmiya, N., Shulman, C., \& Dover, R. (1998). The Autism diagnostic interview- revised and the childhood autism rating scale: Differences between diagnostic systems and comparisons between genders. Journal of Autism and Developmental Disorders, 28, 143-151.

Posserud, M. B., Lundervold, A. J., \& Gillberg, C. (2006). Autistic features in a total population of 7-9 year old children assessed by the ASSQ (Autism Spectrum Screening Questionnaire). Journal of Child Psychology and Psychiatry, 47, 167-175.

Raffaelli, M., \& Duckett, E. (1989). "We were just talking...": Conversations in early adolescence. Journal of Youth and Adolescence, 18, 567-582.

Reaven, J. A., Blakeley-Smith, A., Nichols, S., Dasari, M., Flanigan, E., et al. (2009). Cognitive- behavioral group treatment for anxiety symptoms in children with high-functioning autism spectrum disorders: A pilot study. Focus on Autism and other Developmental Disabilities, 24, 27-37.

Reynolds, C. R., \& Kamphaus, R. W. (2004). Behavior assessment system for children (2nd ed.). Circle Pines, MN: American Guidance Service.

Rucklidge, J. J., \& Tannock, R. (2001). Psychiatric, psychosocial, and cognitive functioning of female adolescents with ADHD. 
Journal of the American Academy of Child and Adolescent Psychiatry, 40, 530-540.

Rutter, M., Bailey, A., \& Lord, C. (2003). SCQ: Social Communication Questionnaire. Los Angeles, CA: Western Psychological Services.

Solomon, M., Goodlin-Jones, B., \& Anders, T. F. (2004). A social adjustment enhancement intervention for high functioning autism, Asperger's syndrome, and pervasive developmental disorder NOS. Journal of Autism and Developmental Disorders, 34, 649-668.

Sukhodolsky, D. G., Scahill, L., Gadow, K. D., Arnold, L. E., Aman, M. G., McDougle, C. J., et al. (2008). Parent-rated anxiety symptoms in children with pervasive developmental disorders: Frequency and association with core autism symptoms and cognitive functioning. Journal of Abnormal Child Psychology, 36, 1573-2835.

Tsai, L. Y., \& Beisler, J. M. (1983). The development of sex differences in infantile autism. The British Journal of Psychiatry, 142, 373-378.
Tsai, L., Stewart, M. A., \& August, G. (1981). Implication of sex differences in the familial transmission of infantile autism. Journal of Autism and Developmental Disorders, 11, 165-173.

Volkmar, F. R., Szatmari, P., \& Sparrow, S. S. (1993). Sex differences in pervasive developmental disorders. Journal of Autism and Developmental Disorders, 23, 579-591.

Wechsler, D. (1999). Wechsler Abbreviated Scale of Intelligence (WASI). San Antonio, TX: Harcourt Assessment.

Wing, L. (1981). Sex ratios in early childhood autism and related conditions. Psychiatry Research, 5, 129-137.

Wood, J. J., Drahota, A., Sze, K., Har, K., Chiu, A., \& Langer, D. A. (2008). Cognitive behavioral therapy for anxiety in children with autism spectrum disorders: A randomized, controlled trial. Journal of Child Psychology and Psychiatry, 50, 224-234.

Yeargin-Allsopp, M., Rice, C., Karapurkar, T., Doernberg, N., Boyle, C., \& Murphy, C. (2003). Prevalence of autism in a US metropolitan area. Journal of the American Medical Association, $289,49-55$. 